\title{
Status of Soil Arthropod in the Natural and Block Plantation Ecosystem of Terminalia arjuna in Bilaspur
}

\author{
Shephalee Thakur ${ }^{1}$, M. Chandrashekharaiah ${ }^{2} *$, M.S. Rathore $^{2}$, \\ Mallikarjuna Lingappa ${ }^{3}$, R.K. Singh ${ }^{1}$, R.B. Sinha ${ }^{2}$ and Alok Sahay ${ }^{2}$ \\ ${ }^{1}$ Dr. C.V. Raman University, Kargi Road Kota, Bilaspur, Chhattisgarh, India \\ ${ }^{2}$ Basic Tasar Silkworm Seed Organisation-Central Silk Board, Bilaspur, Chhattisgarh, India \\ ${ }^{3}$ University of Agricultural Sciences, Bangalore, India \\ *Corresponding author
}

\section{A B S T R A C T}

The Terminalia arjuna (Roxb.) Wight \& Arn. (Combretaceae) is an important commercial

Keywords

Arthropods, Antheraea mylitta, Bilaspur, Natural \& Block Plantation, Soil, Terminalia arjuna

\section{Article Info}

Accepted:

18 February 2019

Available Online:

10 March 2019 crop in India. It has been utilized as a primary food for rearing of the tropical tasar silkworm, Antheraea mylitta by the rural and tribal people in India as a livelihood practice. Due to its continuous utilization for rearing of silkworm, majority of the $T$. arjuna block plantations have been showing sickness and susceptible for variety of pests and diseases. The present study was intended to assess the status of soil arthropods and physical parameters in the natural and block plantations at Bilaspur regions in Chhattisgarh. The study revealed soil arthropods catches in pitfall traps was significantly more compared to Berlese funnel. The Number of insect order recorded in the natural ecosystem of T. arjuna was more compared to T. arjuna Block plantation at Bilaspur and Kargi Kota. In the natural ecosystem of $T$. arjuna, a total of 104 specimens, belonging to 15 different orders were recorded. At $T$. arjuna Block planation Bilaspur and Kargi Kota, a total of 104 and 244 specimens, belonging to 11 and 12 different orders were recorded, respectively. Soil physical characters assessed in the natural ecosystem were more ideal compared to block plantation. Our results suggested that substantial variation in soil arthropods and physicochemical properties between natural and block plantation of T. arjuna ecosystems.

\section{Introduction}

The Terminalia arjuna (Roxb.) Wight \& Arn. (Combretaceae) is an important evergreen tree distributed in Burma, India and Sri Lanka (Dhingra et al., 2013). Since, its multiple utilities as timber, tannin, medicinal, sericulture, firewood, etc., this tree has been considered as a commercial crop in India.
More importantly, the $T$. arjuna is a primary food for the tropical tasar silkworm, Antheraea mylitta. This silkworm being reared by the rural and tribal people in India as a livelihood practice and as a whole, it is being promoted in India as non-forest timber product. Since tropical tasar silkworm is endemic to India, a plan has been made to increase its production from 2908 MT to 6000 
MT during 2030 (BTSSO, 2019). Since, a major part of host plants situated in forest patch, tasar sericulture is being practiced for a short period from July-August and OctoberNovember in a year. Meticulous planning for tasar sericulture along with their regular agriculture practices, it would be more helpful for the rearers in terms of monitory benefit in a short period of time. Though vast areas under tasar flora (sal, Arjuna, Asan, etc.) are existing in India (Chota Nagpur Plateau; Deccan region), not fully utilized for tasar cultivation yet. Since the overall demand for tasar silk far exceeds its supply within India (Pastakia et al., 2015), tasar sericulture is considered to be a potential livelihood sector for rural and tribal Indian.

Apart from quality seed and inputs, the success of crop production also depends on soil status (Usman and Kundiri, 2016). Soil quality, in terms of agriculture practice, interns depend on diversity and richness of soil arthropod and physical status (Cardoso et al., 2013). Scientific analysis in a phased manner reveal variation in soil fauna in the natural and modified ecosystem and it could act as a checkpoint for rectification for sustainable crop production. Since, Surface topsoil is a most active stratum of earth, various bio-geo-chemical processes regulated by the soil-living organism in association with the physical states (solid, liquid and gaseous phases) of soil (Barrios, 2007; Cardoso et al., 2013). More specifically, soil organisms are involved in organic matter decomposition, partial regulation of microbial \& arthropod activities and nutrient cycles (FAO, 2019; Singh, 2000), and are called as bio-indicators of soil fertility. The intensive crop production practices and the use of substandard inputs during crop production have an adverse effect on soil organism and cause depletion of soil diversity (FAO, 2019; Singh, 2000). Presently, the high input agriculture systems gaining least concern about dynamics their soil faunal richness and diversity, and ultimately depends man-made inputs. Such systems are not quite strong enough in regulating natural cycles and sustaining ecosystem structure for a long period. As a result of poor interactions of biotic and abiotic factors as well recycling of nutrients, the productive system becomes nonproductive.

Since tasar silkworm is being reared on host plants which are raised under in-situ conditions; the success in terms of productivity is highly influenced by leaf quality of host plant. The improved production practices like monoculture, structural alteration of the host plant canopy by pruning \& pollarding, modification of microclimate by erecting bunds, circular basin and staggered trenches and application of insecticides, fertilizes, FYM, vermicompost, etc. have been being followed regularly. If soil suffering from sickness, it creates stress on host plants and leads to susceptibility to pests and diseases. Hence, rearing of silkworms on such host plants maintained on productive land to ensure quality new flushes immediately after rearing without compromising its immunity. In this intention, this study was planned to unravel the soil fauna status along with soil physical parameters in the $T$. arjuna ecosystem both in natural and block plantation at Bilaspur region of Chhattisgarh.

\section{Materials and Methods}

The study was conducted at Bilaspur and Kargi Kota T. arjuna Farm, apart from one natural $T$. arjuna filed and lawn in Bilaspur was also selected for comparative study in soil fauna. The Bilaspur is situated between 21'47 and 23'8 North latitudes and 81'14 and 83'15 East Longitudes. The climate is sub-tropical, semi-arid and monsoon type. A total of 2.5 ha area having $7000 \mathrm{~T}$. arjuna plants selected at Bilaspur. Kargi Kota is located at $22.3^{\circ} \mathrm{N}$ $82.03^{\circ} \mathrm{E}$. AMSL $330 \mathrm{~m}$. The climate is similar 
to Bilaspur. A total of 17.5 ha areas having more than 30000 T. arjuna plant at Kargi Kota. An undisturbed area with more $30 \mathrm{~T}$. arjuna plants as natural field and a lawn available in the Basic Tasar Silkworm Seed Organisation campus were selected for the study.

Pit-fall traps were placed in the selected site for 36 hours for the collection of soil macro fauna and in same place soil sample $(15 \mathrm{~cm}$ topsoil) also collected for Berlese funnel experiment. Each pit-fall trap measured $8 \mathrm{~cm}$ height and $6 \mathrm{~cm}$ in diameter. Traps were placed into the soil such that their rims in level with the top surface of the soil. The traps were added with $50 \mathrm{ml}$ water and few drops of glycerol. There was three traps/samples per location were ensured for the observation. Similarly, soil samples (400g) collected were placed carefully along with the labels in
Berlese funnel. The electric bulbs (25W) fixed at the top in the funnel served as the source of light and heat. The apparatus was run for 24 hours. The invertebrates passing through $2 \times 2$ $\mathrm{mm}$ sieve of the sample holder was collected in vials containing $70 \%$ Ethyl alcohol fixed to the lower end of the funnel. These vials were periodically checked to keep the alcohol at desired levels. Labels were kept intact both in the soil sample and faunal extracted vial. After 36 hours, in both experiments, the traps were removed and sorted out and identified the specimens. The experiment was repeated for ten between 4.4.2018 to 20.5.2018.

Physico-chemical properties of surface soil samples collected from Bilaspur and Kargi Kota $T$. arjuna Farm and natural $T$. arjuna ecosystem were analyzed using standard methods mentioned below.

\begin{tabular}{|c|c|c|c|}
\hline S1. No. & Properties & Methodology & Reference \\
\hline 1 & Soil pH & Potentiometry & Jackson (1973) \\
\hline 2 & $\begin{array}{l}\text { Electrical } \\
\text { Conductivity }\end{array}$ & Soil water extraction $(1: 2.5)$ & Jackson (1973) \\
\hline 3 & Organic Carbon & Walkley and Black wet oxidation & Jackson (1973) \\
\hline 4 & Available Nitrogen & Alkaline Potassium Permanganate & Subbiah \& Asija (1956) \\
\hline 5 & Available Phosphorus & $\begin{array}{l}\text { 1: } 0.03 N \mathrm{NH}_{4} \mathrm{~F} \& 0.025 N \mathrm{HCl} \text { (Acid } \\
\text { soil)2: } 0.5 \mathrm{M} \mathrm{NaHCO} \text { (Alkali or neutral } \\
\text { soil) }\end{array}$ & Jackson (1973) \\
\hline 6 & Available potassium & $\begin{array}{l}\text { Neutral } N \mathrm{NH}_{4} \mathrm{OAc} \text { extraction and } \\
\text { Flame photometry }\end{array}$ & Jackson (1973) \\
\hline 7 & Soil Texture & International pipette method & Jackson (1973) \\
\hline
\end{tabular}

\section{Results and Discussion}

Mean catches of soil arthropods in pitfall traps was significantly more compared to Berlese funnel $\quad(\mathrm{t}=5.27 ; \quad \mathrm{df}=16 ; \quad \mathrm{p}<0.01)$. Soil arthropods trapped in the pitfall traps was comparatively more than the Berlese funnel. Only Collembolan, Coleoptera, Diptera, Hymenoptera and Araneae order were recorded in the Berlese funnel. In addition to above, Blattodea, Hemiptera, Lepidoptera,
Neuroptera, Orthoptera, Thysanoptera and Acari were recorded in the pitfall traps (Fig. $1)$.

Number of insect order recorded in the natural ecosystem of $T$. arjuna was more compared to T. arjuna Block plantation at Bilaspur and Kargi Kota $(F=9.84 ; d f=3,39 ; p<0.01)$. The lowest number was recorded in a lawn. Similarly, the ANOVA (Single Factor) indicated that number of soil arthropods 
trapped in lawn $(\mathrm{p}>0.01)$, natural T. arjuna ecosystem ( $>>0.01), \quad T$. arjuna Block plantation at Bilaspur $(\mathrm{p}>0.01)$ and T. arjuna Block plantation at Kargi Kota ( $p>0.01)$ were not significantly varied during different dates.

In the natural ecosystem of $T$. arjuna, a total of 104 specimens, belonging to 15 different orders were recorded. In this site, Collembola, Blattodea, Coleoptera, Dermaptera, Diptera, Hemiptera, Hymenoptera, Isoptera, Lepidoptera, Mantodea, Neuroptera, Orthoptera, Thysanoptera, Araneae and Acari were recorded regularly. At $T$. arjuna Block planation Bilaspur and Kargi Kota, a total of 104 and 244 specimens, belonging to 11 and 12 different orders were recorded, respectively. In both the sites, Collembola, Coleoptera, Diptera, Hemiptera, Hymenoptera, Isoptera, Lepidoptera, Neuroptera, Orthoptera, Araneae and Acari were recorded regularly and in addition to above, Blattodea was recorded at Kargi Kota. In a lawn, only 53 specimens, belonging to nine different orders were recorded. Majorly, Collembolan, Coleoptera, Diptera, Hymenoptera, Araneae, Hemiptera, Lepidoptera, Orthoptera, and Acari were recorded in the lawn (Fig. 2).

Physico-chemical properties of soil that influencing the different orders of Arthropods are given in table 1 . Soil type was sandy clay loam with the low bulk density of 1.16 to 1.23 due to high soil organic matter content (>7.5 $\mathrm{g} / \mathrm{kg}$ ) in all three locations. Soil $\mathrm{pH}$ was neutral in the natural $T$. arjuna ecosystem $(\mathrm{pH}$ = 7.39), whereas, moderately acidic in the $T$. arjuna Block plantation at Kargi Kota $(\mathrm{pH}=$ 5.73) and Slightly acidic in T. arjuna Block plantation at Bilaspur (6.33). The highest mean number of the different order of Arthropods were found in neutral soil $\mathrm{pH}$ as compared to acidic soil $\mathrm{pH}$ conditions. The electrical conductivity of the soil was normal in all three locations with a highest sodium content of $0.38\left(\mathrm{C} \mathrm{mol}\left(\mathrm{P}^{+}\right) \mathrm{kg}^{-1}\right)$ at natural $T$. arjuna ecosystem compared to $T$. arjuna Block plantation at Kargi Kota and T. arjuna Block plantation at Bilaspur. Available nitrogen, phosphorous and potassium content of the soils were medium in all the three locations except available phosphorous content (high - $26.3 \mathrm{~kg} \mathrm{ha}^{-1}$ ) at $T$. arjuna Block plantation at Kargi Kota (Table 1).

In the silkworm seed production process, maintaining optimum leaf nutrient status in host plant is highly prerequisite for desirable growth and development of silkworm. To enable leaf quality standard in terms of protein $(\mathrm{mg} / \mathrm{g}) \quad 15.9 \pm 3.02, \quad$ carbohydrate $\quad(\mathrm{mg} / \mathrm{g})$ $94.867 \pm 17.9$, ascorbic acid (mg/g) 25.24 \pm 5.3 , total Phenol (mg/g) 19.35 \pm 0.589 , nitrogen $(\%)$ 3.05, potassium (\%) 3.06 and phosphorus (\%) 0.18 (Alok Sahay et al., 2018), the optimum nutrient levels in the soil ensured by following recommended nutrient packages. While achieving optimum nutrient status, apart from inorganic input, the organic source of input also considered to sustain and perpetuate soil biodiversity, as they are directly and indirectly related to land productivity and soil building process (Barrios 2007). Among the soil organisms recorded in this study were belong to meso-fauna $(80 \mu \mathrm{m}-2 \mu \mathrm{mm})$ and macrofauna (500 $\mu \mathrm{m}-50 \mathrm{~mm})$ (Swift et al., 1979). Maximum number and frequently recorded insect order were Hymenoptera, Collembola, Coleoptera, Araneae, Acari and Lepidoptera. UNEP (1995) estimate suggested that nearly macro-fauna ranges from $53.3 \%$ to $58.7 \%$ and mesofauna ranges from $2.2 \%$ to $27.1 \%$. Soil organisms vary with respect to life-stage specific, available resource, biotic and abiotic factors. Giller et al., (1997) demonstrated that physical factor such as soil moisture content, soil temperature and presence of litter were the major constituents determine the abundance and vertical distribution of soil micro-arthropods. Soil mesofauna uses existing pore space or channels for 
locomotion. Further, they act as predators on other soil animals as well as microorganisms and also feed on animal material, live or decaying plant material, fungi, algae, lichen, spores, and pollen. By these processes, mesofauna plays an important role in increase nitrogen mineralization (Hassink et al., 1993). Among the mesofauna, collembolan and mites are major insect order recorded in this study.

Table.1 Physical parameter analyzed for the soil collected from T. arjuna ecosystem with natural and block plantation (Kargi Kota and Bilaspur) ecosystem

\begin{tabular}{|c|c|c|c|}
\hline Particulars & $\begin{array}{l}\text { Natural T. arjuna } \\
\text { ecosystem }\end{array}$ & $\begin{array}{c}\text { T. arjuna Block } \\
\text { plantation at Kargi Kota }\end{array}$ & $\begin{array}{c}\text { T. arjuna Block } \\
\text { plantation at Bilaspur }\end{array}$ \\
\hline pH & 7.39 & 5.73 & 6.33 \\
\hline $\operatorname{EC}\left(\mathrm{dS} \mathrm{m}^{-1}\right)$ & 0.23 & 0.11 & 0.22 \\
\hline OC (g per kg) & 8.70 & 9.50 & 10.20 \\
\hline $\mathbf{N}\left(\mathrm{kg} \mathrm{ha}^{-1}\right)$ & 244.6 & 203.7 & 207.16 \\
\hline $\mathrm{P}_{2} \mathrm{O}_{5}\left(\mathrm{~kg} \mathrm{ha}^{-1}\right)$ & 16.40 & 26.3 & 15.70 \\
\hline $\mathbf{K}_{2} \mathbf{O}\left(\mathrm{kg} \mathrm{ha}^{-1}\right)$ & 331.80 & 246.8 & 280.50 \\
\hline $\mathrm{Na}\left(\mathrm{C} \mathrm{mol}\left(\mathrm{P}^{+}\right) \mathrm{kg}^{-1}\right)$ & 0.38 & 0.19 & 0.18 \\
\hline Bulk Density & 1.16 & 1.16 & 1.23 \\
\hline Particle Density & 2.09 & 2.19 & 2.37 \\
\hline Sand $(\%)$ & 58.4 & 52.7 & 52.8 \\
\hline Silt (\%) & 13.3 & 19.8 & 19 \\
\hline Clay (\%) & 28.2 & 27.6 & 28.2 \\
\hline Texture & Sandy clay loam & Sandy clay loam & Sandy clay loam \\
\hline
\end{tabular}

Fig.1 Efficacy of pitfall trap and Berlese funnel trap in the trapping of soil arthropods

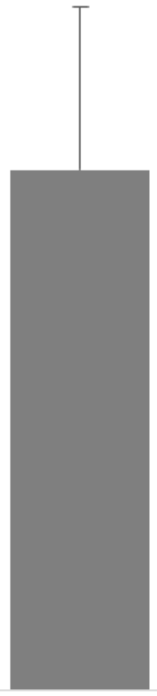

Pitfall trap

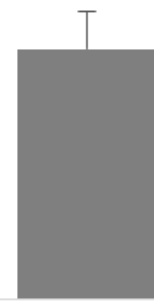

Berlese funnel 
Fig.2 Mean $( \pm$ SD) number of arthropod orders recorded in the pitfall traps in a different ecosystem

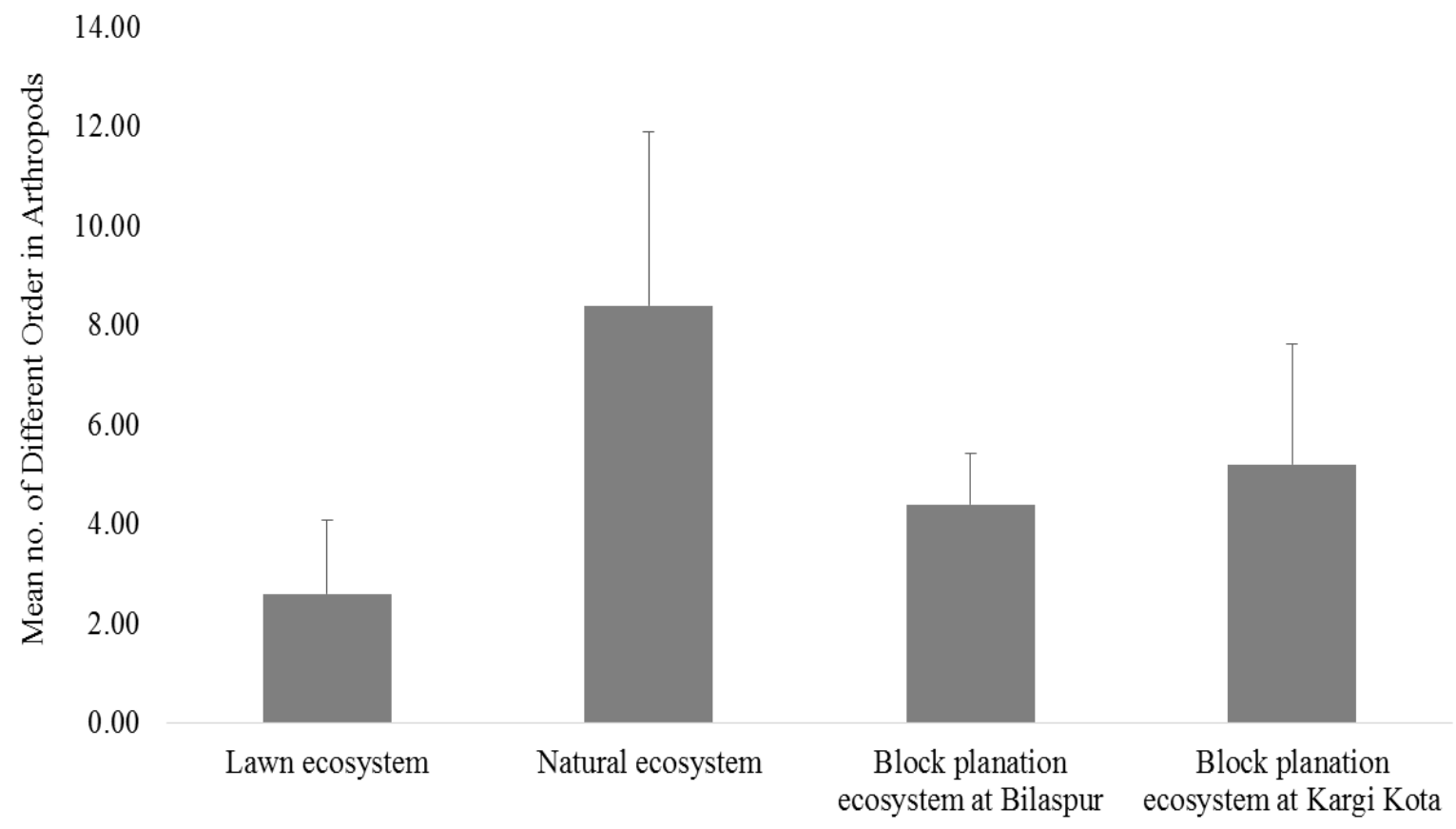

The collembolans are directly influencing the nitrogen mineralization, soil respiration, leaching of dissolved organic carbon, fungal feeding, fungal propagules distribution, root herbivory and predation on nematodes (Filser, 2002). Mites feed on living or dead parts of plants or fungi and also act as predators, scavengers and play an important role in the soil structure formation and decomposition (Behan-Pelletier, 1999).

Macrofauna complex play a direct or indirect role in biodegradation \& humification of organic residues, aggregation, aeration, porosity, water infiltration \& retention, resistance to erosion, dispersal of mycorrhizal fungi, etc. (Ayuke, 2010). The cockroaches (Blattodea) are omnivores or detritivores and live in a range of habitats such as among leaf litter, in rotting wood, in thick vegetation, in crevices, in cavities beneath bark, under logs and among debris and recycle nutrients and energy back into the ecosystem (Bell et al., 2007). Coleopterans are the most abundant and varied group of soil-dwelling insects and they are major predators on other insects and also involved in decomposition by feeding on organic matter, indirectly influence on microbial communities (Hengeveld, 1980; Wolters, 2000). The earwigs Dermaptera are also litter transformers and generally called as scavengers, but some are omnivorous or predatory (Burton and Maurice, 2002). Dipterans are phytosaprophagous organisms, microphages, scrapers, mycophagous organisms and predators, but they also play an important role in leaf-litter decomposition and nutrient cycling (Frouz, 1999). The role of Hemiptera, Neuroptera and Mantodea as soil organism is not known, but, they are general predators. Hymenopterans are scavengers and culturing fungi for food (Culliney, 2013). Isopterans feed on hummus, partly decomposed plant matter in the soil and wood and litter. They also culture microbes (Kühnelt, 1976; Luscher, 1951). Lepidoptera is also a large group of insect order and they transform plant matter into animal matter and in turn serve as food for many other groups of animals (Tobi et al., 1993). Orthoptera and 
Thysanoptera are terrestrial herbivore insect pests and play important role maintenance of food cycle (Bettio et al., 2002). Araneae are a major predator on herbivores, saprophages, microphytophages and predators and influence both in the grazing and detrital food chains (Kajak, 1995).

The variation in soil arthropods composition and soil parameters was very much evident from this study. Banerjee (1982) reported a positive relation between acari and soil moisture and organic carbon. The relationship between soil physical parameters and abundance of soil arthropods should be drawn for better understanding of the dependence of soil arthropods. Hence, crop production practices/measures can be developed to enhance the crop yield. In this study, abundance of soil arthropods was recorded under natural ecosystem of $T$. arjuna compared to block plantation.

\section{References}

Ayuke, F.O., 2010. Soil macro-fauna functional groups and their effects on soil structure, as related to agricultural management practices across agroecological zones of Sub-Saharan Africa. $\mathrm{PhD}$ Thesis, Wageningen University, Wageningen, NL.

Barrios, E., 2007. Soil biota, ecosystem services and land productivity. Ecol. Econ. 64, 269-285.

Basic Tasar Silkworm Seed Organisation (BTSSO), 2018, Vision \& Mission, http://www.btsso.org/mission.php.

Behan-Pelletier, V.M., 1999. Oribatid mite biodiversity in agroecosystems: role for bio-indication. Agriculture, Ecosystems and Environment. 74: 411-423.

Bell, W.J., Roth, W.L. and Nalepa, C.A., 2007. Cockroaches ecology, behavior, and natural history. The Johns Hopkins University Press, Baltimore.
Banerjee, S., 1982. Qualitative and quantitative composition of oribatid mites (Acarina) in relation to certain soil factors. Acarology VI (Eds. Griffiths, D.A., and Bowman) - Vol. 2 Ellis Horwood Limited England, pp. 878-885.

Bettiol, A., Ghini, R., Galvao, J.A.H., Ligo, M.A.V. and Mineiro, J.L.D.C., 2002. Soil organisms in organic and conventional cropping systems. Scientia Agricola. $\quad 59(3): \quad$ 565-572. dx.doi.org/10.1590/S010390162002000300023.

Burton and Maurice, 2002. International wildlife encyclopedia. 1 ( $3^{\text {rd }}$ ed.). New York: Marshall Cavendish. ISBN 9780-7614-7266-7.

Cardoso, K.L.B.N., Vasconcellos, R.L.F., Binil, D., Miyauchi, M.Y.H., Santos, C.A.D., Alves C.R.L., Paula, A.M.D., Nakatani, A.S., Pereira, J.D.M. and Nogueira, M.A., 2013. Soil health: looking for suitable indicators. What should be considered to assess the effects of use and management on soil health? Sci. Agric. 70(4): 274-289.

Culliney, T,W., 2013. Role of Arthropods in Maintaining Soil Fertility, Agriculture. 3:

629-659; doi:10.3390/agriculture3040629.

Dhingra, V., Dhingra, S. and Singla, A., 2013, Forensic and pharmacognostic studies of the Terminalia arjuna Bark. Egypt. J. For. Sci., 3: 15-19.

Filser, J., 2002. The role of Collembola in carbon and nitrogen cycling in soil: Proceedings of the $\mathrm{X}^{\mathrm{th}}$ international Colloquium on Apterygota, Ceske Budejovice 2000: Apterygota at the Beginning of the Third Millennium. Pedobiologia, 46(3-4): 234-245.

Food and Agricultural Organisation (FAO), 2019. AGP - Agriculture and soil biodiversity. http://www.fao.org/ agriculture/crops/thematic-sitemap/ 
theme/spi/soilbiodiversity/agricultureand-soil-biodiversity/en/\#

Frouz, J., 1999. Use of soil dwelling Diptera (Insecta, Diptera) as bioindicators: a review of ecological requirements and response to disturbance. Agric. Ecosyst. Environ., 74: 167-186. doi:10.1016/S0167-8809(99)00036-5.

Giller, K.E., Beare, M.H., Lavelle, P., Izac, A.M., Swift, M.J., 1997. Agricultural intensification, soil biodiversity and agroecosystem function. Applied Soil Ecology, 6(1): 3-16.

Hassink, J., Bouwman, L.A., Zwart, K.B. and Brussaard, L., 1993, Relationships between habitable pore space, soil biota and mineralization rates in grassland soils. Soil Biology and Biochemistry, 25(1): 47-55. doi:10.1016/00380717(93)90240-C.

Hengeveld, R., 1980. Polyphagy, oligophagy and food specialization in ground beetles (Coleoptera: Carabidae). Neth. J. Zool., 30: 564-584.

Kajak, A., 1995. The role of soil predators in decomposition processes, Eur. J. Entomol., 92(3): 573-580.

Luscher, M., 1951. Significance of 'Fungus Gardens' in Termite Nests. Nature, 167: 34-35.

Pastakia, A., Alam, S., Satyanarayan, K.,
Pandya, H., Dahal, B.R. and Khandai, R., 2015. Reel of fortune building inclusive value chains: the case of tasar silk in Bihar and Jharkhand. PRADAN, New Delhi.

Singh, R.B., 2000. Environmental consequences of agricultural development: a case study from the Green Revolution state of Haryana, India. Agriculture, Ecosystems and Environment, 82: 97-103.

Swift, M.J., Heal, O.W. and Anderson, J.M., 1979. Decomposition in terrestrial ecosystems. University of California Press, Berkeley.

Tobi, D.R., Grehan, J.R. and Parker, B.L., 1993. Review of the ecological and economic significance of forest Hepialidae (Insecta: Lepidoptera). Forest Ecology and Management, 56(14), 1-12; doi.org/10.1016/03781127(93)90099-9.

Usman, S. and Kundiri, A.M., 2016. Role of Soil Science: An Answer to Sustainable Crop Production for Economic Development in Sub-Saharan Africa. International Journal of Soil Science, 11: 61-70.

Wolters, V., 2000. Invertebrate control of soil organic matter stability. Biol. Fertil. Soils, 31: 1-19.

\section{How to cite this article:}

Shephalee Thakur, M. Chandrashekharaiah, M.S. Rathore, Mallikarjuna Lingappa, R.K. Singh, R.B. Sinha and Alok Sahay. 2019. Status of Soil Arthropod in the Natural and Block Plantation Ecosystem of Terminalia arjuna in Bilaspur. Int.J.Curr.Microbiol.App.Sci. 8(03): 2131-2138. doi: https://doi.org/10.20546/ijcmas.2019.803.255 